\title{
Wind tunnel measurement of flow and dispersion over urban area
}

\author{
Petr Michálek ${ }^{1, *}$ and David Zacho ${ }^{1}$ \\ ${ }^{1}$ Department of Aerodynamics, Aerospace Research and Test Establishment (VZLU), Beranových 130, Praha 9, Czech Republic
}

\begin{abstract}
Measurements of flow and dispersion over urban area model were conducted in the boundary layer wind tunnel in VZLU. Scale model of an industrial area with its residential neighborhood was equipped with ground-level emission source and the flow and dispersion of emissions was measured. Flow field was studied using hot wire anemometer and concentration field was studied using flame ionization detector. These measurements were used for the verification of a new computational model of emission flow and dispersion, which was developed in VZLU.
\end{abstract}

\section{Introduction}

There are many industrial areas near historical centers of cities or residential areas in the Czech Republic. This fact presents a possible threat to the lives and properties of people living in these areas by escape of dangerous gases.

A new computational model for flow and gas dispersion in the atmospheric boundary layer was developed in VZLU. The computational model is based on numerical simulation of compressible gas flow in the gravitational field and finite volume method of Reynolds-averaged Navier-Stokes equations. The software uses pre-calculated results of flow and dispersion in chosen areas near chemical plants in Czech Republic together with actual meteorological data to estimate the most dangerous area. The estimate will be used by rescue services and firemen to make the rescue action more effective or by the local authorities for preparation of emergency evacuation plans.

This field of research was studied e.g. by Hall et al. [1], Lawton and Robins [2], Yassin et al. [3]. Previous dispersion studies in VZLU dealt with simple dispersion cases, i.e. change in roughness [4], rectangular building [5], terrain wave and slope [6]. Large terrain model in scale 1:1500 was used in [7]. Details about the computational model can be found in $[8,9]$.

\section{The experiment}

The experimental work was done in the boundary layer wind tunnel (BLWT) in VZLU, a. s. The BLWT is an open-circuit wind tunnel with cross section $1.8 \mathrm{~m}$ wide and $1.5 \mathrm{~m}$ high with adjustable ceiling. The test section for boundary layer development is $13.6 \mathrm{~m}$ long. The tunnel is powered by $55 \mathrm{~kW}$ fan. Maximal velocity above the boundary layer is ca. $24 \mathrm{~m} \mathrm{~s}^{-1}$. Reference velocity above the boundary layer is measured with
Pitot-static probe and hot-wire probe. The model space is equipped with $1.75 \mathrm{~m}$ dia. turntable and traversing device for moving the probe in all three directions $\mathrm{x}, \mathrm{y}$, z. The simulation means can create agricultural, suburban or urban boundary layer according to Eurocode 1 [10]. The boundary layer developed over the entire test section with plastic sheet with $7 \mathrm{~mm}$ high truncated cones and a rectangular barrier $140 \mathrm{~mm}$ high, which served as turbulence generator. This boundary layer corresponds with terrain type III (suburban).

\subsection{The urban area model}

The model of the area of interest was manufactured from lightweight boards on the basis of a digital terrain model of the Liberec city. The model was made in scale 1:300 and presents an area of ca. $870 \mathrm{~m} \times 500 \mathrm{~m}$ in full scale. The building models were simplified into blocks and cut out of synthetic wood. The model is shown in Figure 1, where wind direction is from upper left to bottom right corner. The modeled area followed the valley of Lužická Nisa river in southeast-northwest direction. The emission source is a small chamber $25 \times 25 \times 10 \mathrm{~mm}$ covered with filtration fabric on its top and built in the model. The source presents a ground level point or small area source of gas emissions. Two possible locations of the source were studied, i.e. behind the chimney and behind the gas tanks. This paper presents the results of the case where the emission source was located near the gas tanks. The map of the modeled area with marked position of the sources is presented in Figure 2. 


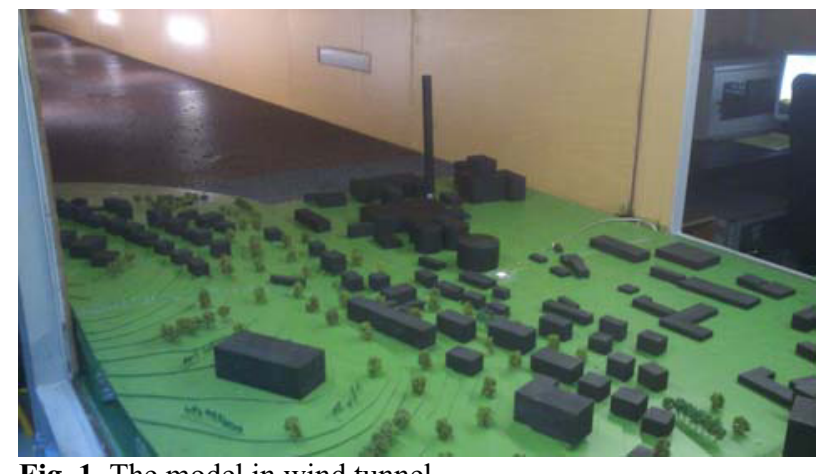

Fig. 1. The model in wind tunnel

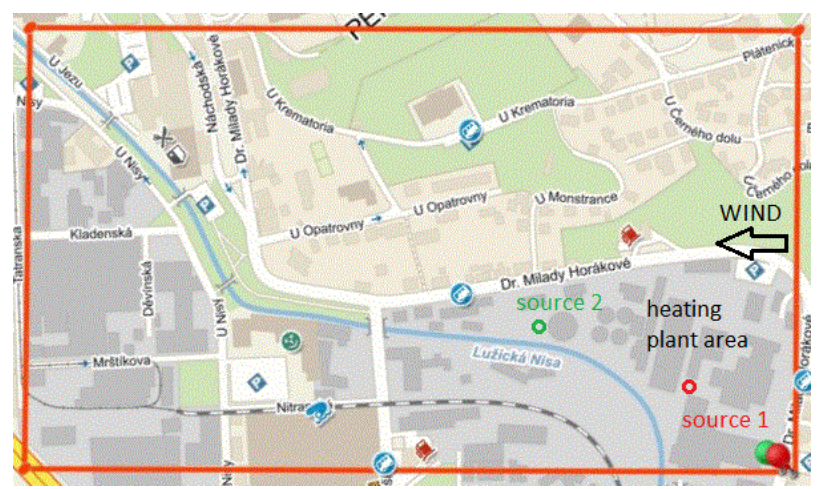

Fig. 2. The modeled area

\subsection{Flow and dispersion measurements}

The flow field of the incoming boundary layer was measured with dual-sensor hot-wire probe and the concentration field was measured with flame ionization detector. The vertical mean velocity profile is shown in Figure 3, where $U\left(\mathrm{~m} \mathrm{~s}^{-1}\right)$ is longitudinal component of velocity vector and $\mathrm{V}\left(\mathrm{m} \mathrm{s}^{-1}\right)$ is perpendicular velocity vector component, $I_{u}(\%)$ is turbulence intensity of the component $U, I_{v}(\%)$ is turbulence intensity of the component $\mathrm{V}$ and $\mathrm{z}(\mathrm{mm})$ is vertical height above the ground. $\mathrm{U}_{\text {red }}$ is reduced part of $\mathrm{U}$, which was used for the logarithmic fit of the mean velocity profile.

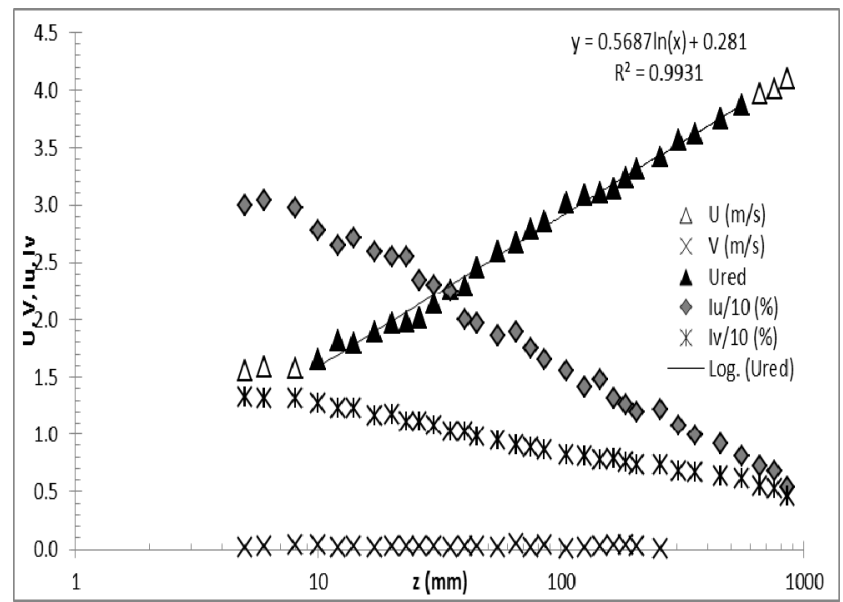

Fig. 3 The boundary layer velocity profile

The wind tunnel velocity was set to ca. $4.3 \mathrm{~m} \mathrm{~s}^{-1}$ above the boundary layer and this reference velocity was used in the dispersion experiments as well. For this size of the modeled area, the so-called small-scale similarity criteria applies, which means that the minimal Reynolds roughness number $\mathrm{Re}^{*}$ has to be satisfied. This ensures invariance of the flow pattern around the structure on the main flow velocity. The Reynolds roughness number is defined as

$$
\mathrm{Re}^{*}=\mathrm{z}_{0} \times \mathrm{u}^{*} / \mathrm{v}=9.3 \geq 1
$$

where $v$ is kinematic viscosity of air $\left(\mathrm{m}^{2} \mathrm{~s}^{-1}\right), \mathrm{u}^{*}$ is frictional velocity $\left(\mathrm{m} \mathrm{s}^{-1}\right)$ and $\mathrm{z}_{0}$ is aerodynamic roughness $(\mathrm{m})$. Values of $\mathrm{u}^{*}=0.23 \mathrm{~m} \mathrm{~s}^{-1}$ and $\mathrm{z}_{0}=0.61$ $\mathrm{mm}$ were derived from the logarithmic fit of the mean velocity profile.

The emission source was connected to the gas tank with ethane as tracer gas and to the compressed air source via flow controllers. For neutral (non-buoyant) emission modeling, a mixture of compressed air with volume flow $5.11 \mathrm{~min}^{-1}$ and ethane with flow $0.251 \mathrm{~min}^{-}$ 1 was used. Concentration field was measured using suction tube mounted on a traversing device, necessary tubing, peristaltic pump and a flame ionization detector (FID). FID calibration was made with calibration gas mixture with precise concentration $100 \mathrm{ppm}$ (parts per million) of ethane in air. Sampling time was set to $60 \mathrm{~s}$ for one point, and then the probe moved to next point and waited $30 \mathrm{~s}$ to clean the tubing from previous sample. The response of this system is up to $10 \mathrm{~Hz}$ that is why only mean concentration values were evaluated. FID signals were recorded in the computer using analog to digital input card and LabView software.

Regarding the terrain configuration, which includes high slope in its northern part, measurements were made in available area in the nearest neighborhood of the heating plant and the river valley. The local flow velocity was studied in horizontal and vertical profiles. Concentration fields were studied in a network of points at heights 10, 25, $50 \ldots 200 \mathrm{~mm}$ above the source level. The practical realization of the experiment was quite difficult, because all model buildings and terrain had to be avoided; therefore some areas of the model were not measured.

\section{Results and discussion}

The resulting image from measurements within a network of points processed as contour graph at the lowest height $10 \mathrm{~mm}$ ( $3 \mathrm{~m}$ in full scale) above the source level is shown in Figure 4. The coordinates xFS (m) and yFS (m) are in full scale values. The source was at the right tip of the measured area and is marked with black square. Crosses indicate measuring points and the main flow direction is from right to left. This height was the lowest height above the model surface, where measuring was possible in practice. The plume extension behind the source can be observed. Figure 5 shows concentration field at height $25 \mathrm{~mm}$ (7.5 m in full scale). The maximal concentration is about half of the one in Figure 4. Figure 6 presents the concentration field at height $50 \mathrm{~mm}(15 \mathrm{~m}$ in full scale) and maximal concentration value almost one third of the maximal value in Figure 5. One can see 
that the concentration is rapidly decreasing with height. The concentration field from Figure 4 (lowest level) was placed over a satellite image, so that the extent of the plume can be evaluated in real environment, as shown in Figure 7.

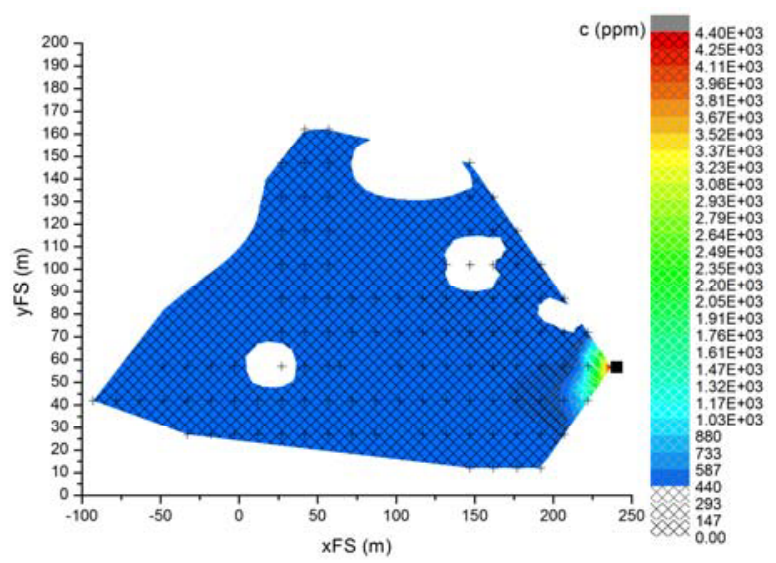

Fig. 4. Concentration field at $\mathrm{z}=10 \mathrm{~mm}$

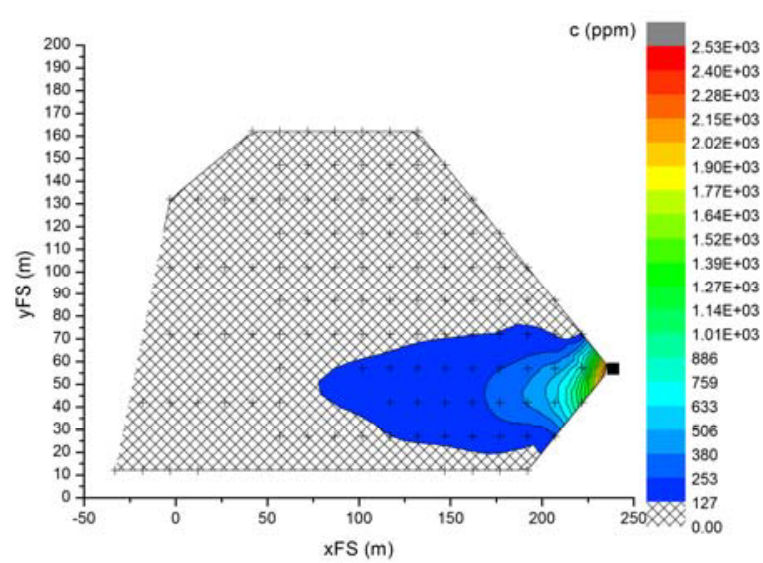

Fig. 5. Concentration field at $\mathrm{z}=25 \mathrm{~mm}$

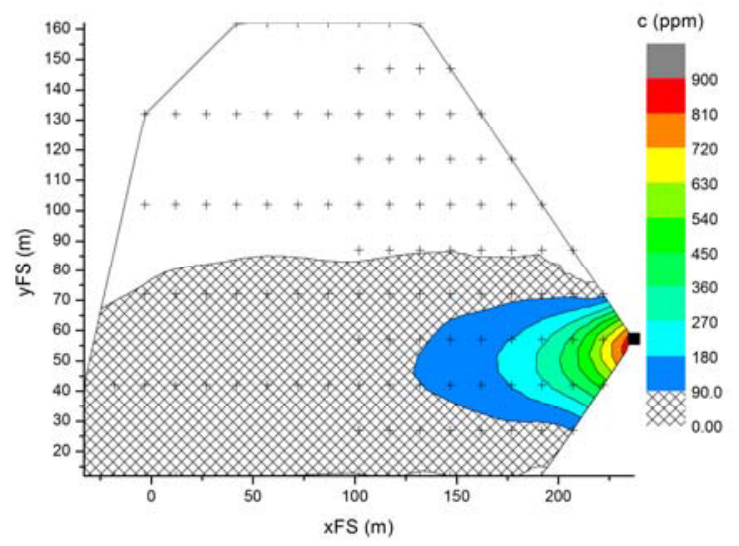

Fig. 6. Concentration field at $\mathrm{z}=50 \mathrm{~mm}$

\section{Conclusion}

Concentration fields over a detailed "city scale" model of urban area in Liberec were measured in the BLWT in VZLU. Mean concentration and velocity profiles and fields were measured with the use of tracer gas emission, flame ionization detectors and hot-wire probes. The extent of the plume from simulated gas leakage from a heating plant in Liberec was determined horizontally and vertically. The mean concentration fields were measured in order to use them for verification and validation of the numerical dispersion model.

Authors thank the support from the Ministry of the Interior of Czech Republic, project VG20122015098.

\section{References}

1. D.J. Hall, V. Kukadia, S. Walker, P. Tilz, G.W. Marsland, Proceedings of Physmod 2007 (2007)

2. T. Lawton, A. Robins, Proceedings of Physmod 2007 (2007)

3. M.F. Yassin, M. Ohba, H. Tanaka, Proceedings of 14th joint conference on application of air pollution meteorology with the air and waste management Assoc, Atlanta, Georgia, USA, 1-9, (2006)

4. P. Michálek, D. Zacho, Air Pollution XX (2012)

5. P. Michálek and D. Zacho, Int. J. Sust. Dev. Plan. 10, p. 203-206 (2015)

6. P. Michálek, D. Zacho, Experimental Fluid Mechanics 2014, p. 366 (2014)

7. P. Michálek, D. Zacho, Engineering Mechanics 2015, p.85 (2015)

8. M. Kyncl, Numerical solution of the threedimensional compressible flow. Ph.D. thesis, MFF UK, Prague (2011)

9. M. Kyncl, J. Pelant, Technical report $R-5453$, VZLU, Prague (2012)

10. Eurocode 1: Actions on structures - Part 1-4: General actions - Wind loads (EN 1991-1-4), European Committee for Standardisation, Brussels (2005) 


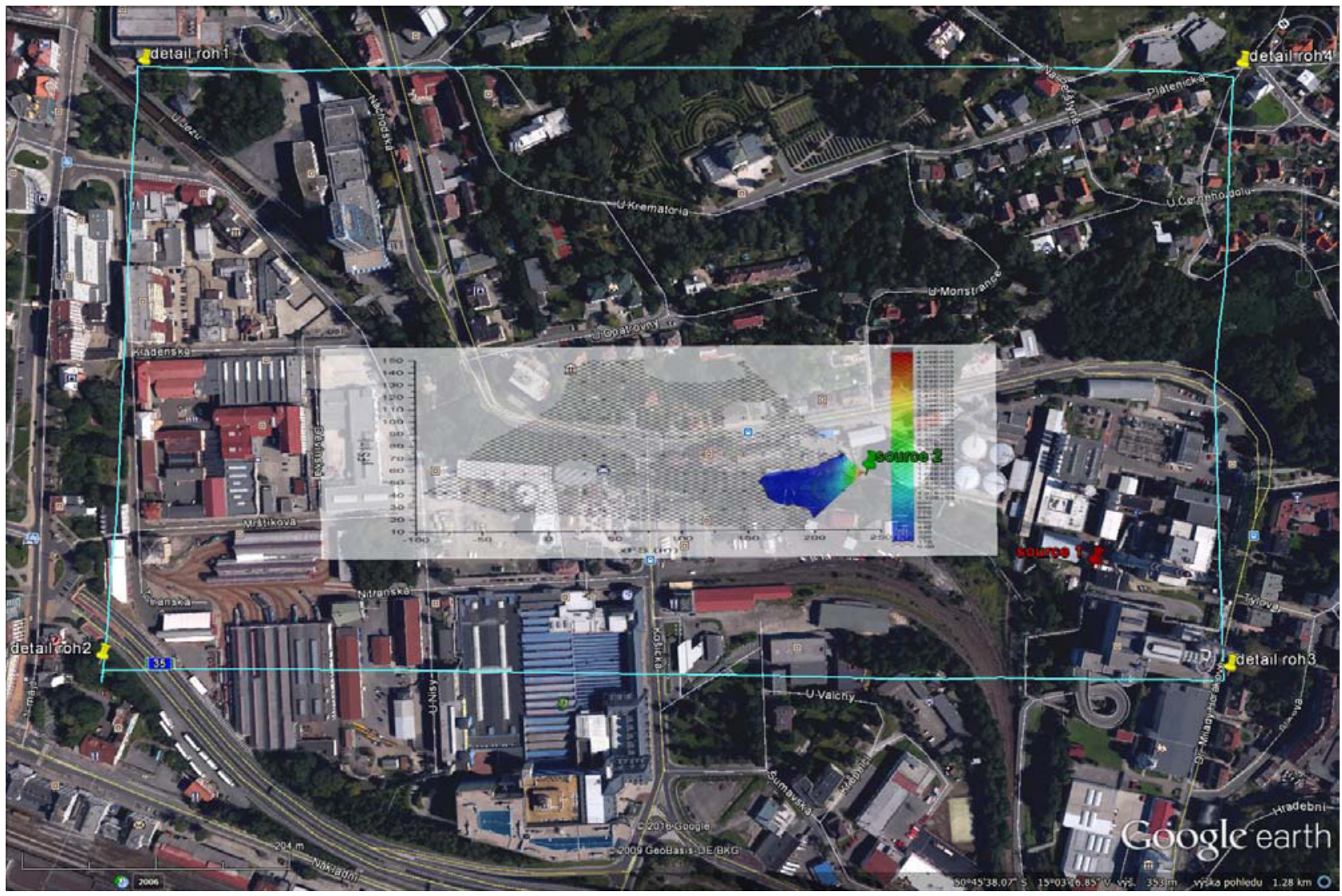

Fig. 7. Concentration field compared with photomap 